\title{
AVALIAÇÃO DE LINGUIÇAS DE TILÁPIAS DO NILO (OREOCHROMIS NILOTICUS) SUBMETIDAS A DIFERENTES MÉTODOS DE DEFUMAÇÃO
}

\author{
PAULO ROBERTO CAMPAGNOLI DE OLIVEIRA FILHO ${ }^{1}$ \\ PAULO VITOR MELO REIS ${ }^{2}$ \\ ISABELLY BARBOSA DE ARAÚJO ${ }^{3}$ \\ LITO JORGE RAUL ${ }^{4}$ \\ NEIDE KAZUE SAKUGAWA SHINOHARA ${ }^{5}$ \\ TITO EDUARDO LLERENA DAZA ${ }^{6}$
}

\begin{abstract}
Uma forma de diversificar e estimular o consumo de peixes no Brasil pode ocorrer com a elaboração de produtos inovadores como as linguiças defumadas. Portanto, oobjetivo do presente estudofoiavaliar aspectos nutricionais (proteína bruta, gordura, umidade e cinzas), físicas (perda de peso e encolhimento, capacidade de retenção de água, textura e cor instrumental e $\mathrm{pH}$ ), química (atividade de água) e bacteriológicas (Escherichia coli, Salmonella spp., Staphylococcus coagulase positiva e bactérias aeróbias psicrotróficas) de linguiças de filés de tilápias do Nilo submetidas a defumação tradicional e líquida. As linguiças submetidas a defumação líquida apresentaram maior percentual proteico, maior valor de $L^{*}$ (luminosidade), menor valor de $a^{*}$ (vermelho) e $b^{*}$ (amarelo) porém com maior perda de peso durante o processamento e menor capacidade de retenção de água. Os teores de umidade, gordura, cinzas, porcentagem de encolhimento, textura instrumental, $\mathrm{pH}$, atividade de água e análises bacteriológicas não foram influenciadas por ambos os métodos de defumação aplicados. Portanto, a defumação líquida causa melhora nos percentuais de proteínas, pouca variação nos aspectos físicos, químicos e bacteriológicos de linguiças elaboradas com filés de tilápias do Nilo em relação ao método tradicional, além de apresentar maior facilidade de execução, menor poluição ambiental, mais fácil limpeza após o processamento e menor possibilidade de deposição de compostos químicos cancerígenos, sendo um potencial substituto do método tradicional de defumação de linguiças de tilápias do Nilo.
\end{abstract}

PALAVRAS-CHAVES: DEFUMAÇÃO TRADICIONAL, DEFUMAÇÃO LIQQUIDA, EMBUTIDOS DE PESCADO, OREOCHROMIS NILOTICUS.

1 Professor Doutor pertencente ao Departamento de Pesca e Aquicultura, UFRPE, Recife, Pernambuco (email: paulocoliveira79@hotmail.com).

2 Graduando do curso de Engenharia de Pesca da UFRPE, Recife, Pernambuco (email: pvictor_reis@hotmail. com).

3 Mestranda do curso de Pós-graduação em Recursos Pesqueiros e Aquiculturada UFRPE, Recife, Pernambuco (email: isabelly.barbosa.a@gmail.com).

4 Mestre em Recursos Pesqueiros e Aquiculturada UFRPE, Recife, Pernambuco (email: litoraulmandede@ gmail.com).

5 Professora Doutora pertencente ao Departamento de Tecnologia Rural, UFRPE, Recife, Pernambuco (email: neideshinohara@gmail.com).

6 Doutorando do curso de Pós-graduação em Recursos Pesqueiros e Aquiculturada UFRPE, Recife, Pernambuco (email: telld@lamolina.edu.pe). 


\section{INTRODUÇÃO}

O consumo de pescado no Brasil (aproximadamente $10 \mathrm{~kg} / \mathrm{hab}$ ) está abaixo do mínimo recomendável pela OMS (12kg/hab) (FAO, 2016), e a elaboração de produtos inovadores utilizando a carne de pescado pode ser capaz de estimular o setor de processamento e melhorar o consumo interno. Dentre as espécies nacionais que poderão estimular o consumo de pescado está a tilápia do Nilo que é atualmente a mais cultivada por apresentar alta rusticidade, fácil adaptabilidade, carne nutritiva e de ótima qualidade sensorial (SÁ VIEIRA et al., 2015). No entanto, devido ser um alimento muito perecível, formas de conservação e processamento devem ser estudadas. Uma delas é com a utilização da carne do pescado para serem utilizados como matérias-primas em produtos tecnológicos como as linguiças defumadas, que além de ser muito bem aceito pelo consumidor, pode apresentar vida útil estendida pelo processo de defumação.

A preservação da defumação do pescado e produtos de pescado ocorre pela ação do sal, inativação térmica de bactérias deteriorantes, deposição de componentes antimicrobianos e antioxidantes presentes na fumaça, diminuição da umidade e atividade de água (RIZO et al., 2015; BOUZGANOU et al., 2016). O método tradicional de defumação é com a queima de madeira e calor de cozimento $\left(80-90^{\circ} \mathrm{C}\right)$ em um processo de aproximadamente 4 a 5 horas (SOUZA et al., 2004). No entanto, outas técnicas tem sido testadas. Dentre elas a defumação líquida é uma das mais promissoras por ser um processo mais limpo, com menor poluição ambiental, possibilidade de uma grande variedade de fumaças, maior uniformidade de cor e sabor, alta deposição de substâncias antioxidantes e antimicrobianas e menor deposição de compostos cancerígenos como hidrocarbonetos e benzopirenos (COSTA et al., 2008).

A estabilidade físico-química, microbiológica e sensorial de mortadelas defumadas da maneira tradicional elaboradas com carne mecanicamente separada de resíduos de filetagem de tilápias do Nilo (Orechromis niloticus) mantidas durante 30 dias a $6^{\circ} \mathrm{C}$ foi avaliada por BARTOLOMEU et al. (2014). Os autores observaram não ter havido presença de bactérias patogênicas, estabilidade do $\mathrm{pH}$ e boa aceitação do produto. Em outro estudo foi comparado aspectos microbiológicos, químicos e sensoriais de linguiças elaboradas com carne de C. regium, L. mystaceus e C. trutta, submetidas a defumação tradicional ou líquida e mantidas a $4^{\circ} \mathrm{C}$ (OZPALAT \& PATIR, 2016). Foi observado aumento na contagem microbiana, diminuição do $\mathrm{pH}$, aumento nos valores de oxidação lipídica e bases nitrogenadas voláteis e diminuição na aceitação sensorial com o passar dos dias alcançando o limite máximo de 56 dias de armazenagem a $4^{\circ} \mathrm{C}$. No entanto, os processos de defumações testados não influenciaram nos aspectos de qualidade.

Apesar de haver alguns estudos avaliando aspectos tecnológicos de linguiças de pescado defumadas ainda não foi encontrado na literatura estudo sobre linguiças elaboradas com filés de tilápias do Nilo submetidas a diferentes formas de defumação. Portanto, o objetivo do presente estudo foi avaliar aspectos nutricionais, físicos, químicos e bacteriológicos de linguiças elaboradas com filés de tilápias submetidas ao processo de defumação tradicional e líquida.

\section{MATERIAL E MÉTODOS}

\subsection{MATÉRIAS-PRIMAS}

Foram utilizadas tilápias do Nilo (Oreochromis niloticus) adquiridas resfriadas no comércio local de Recife-PE. Os peixes foram acondicionados em caixas térmicas com gelo em escamas e levados até o Laboratório de Tecnologia do Pescado, pertencente ao Departamento de Pesca e Aquicultura da Universidade Federal Rural de Pernambuco (UFRPE), Recife, PE. Os peixes foram lavados com água clorada (5 ppm) para a retirada do muco superficial e filetados. Após a filetagem, a matéria-prima cárnea foi congelada em freezer comercial $\left(-20 \pm 2{ }^{\circ} \mathrm{C}\right)$ e mantida nesta condição até a elaboração das linguiças. 


\subsection{FORMULAÇÕES}

As formulações foram calculadas para obtenção de aproximadamente $3.000 \mathrm{~g}$ de massa de linguiça de cada tratamento (defumação tradicional ou com fumaça líquida - Defumax, Kraki ${ }^{\circledR}$ ). Os demais ingredientes foram: sal comum $(\mathrm{NaCl})$, condimento de linguiça Calabresa - Sal comum, especiarias naturais e aromatizantes naturais (Condimento Calabresa 399, Kraki ${ }^{\circledR}$ ), sal de cura - sal, nitrito e nitrato de Sódio (Pó Húngaro III, Kraki ${ }^{\circledR}$ ), estabilizante -INS 451i (Tripolifosfato de sódio) (Krakoline E, Kraki ${ }^{\circledR}$ ), antioxidante - açúcar e antioxidante INS 316 (Isoascorbato de sódio) (Fixador A80 - Kraki ${ }^{\circledR}$ ), nos quais foram adicionados nas mesmas proporções em ambos os tratamentos (TABELA 1).

\section{TABELA 1 - FORMULAÇÕES DE LINGUIÇAS ELABORADAS COM FILÉS DE TILÁPIAS DO NILO (OREOCHROMIS NILOTICUS) SUBMETIDAS À DEFUMAÇÃO LÍQUIDA E DEFUMAÇÃO TRADICIONAL}

\begin{tabular}{ccc}
\hline Ingredientes $(\mathrm{g})$ & \multicolumn{2}{c}{ Tipos de Defumação } \\
\cline { 2 - 3 } & Defumação líquida & Defumação tradicional \\
\hline Filés de tilápias & $2.925,0$ & $2.940,0$ \\
Sal comum $(0,3 \%)$ & 9,0 & 9,0 \\
Sal de Cura $(0,2 \%)$ & 6,0 & 6,0 \\
Antioxidante $(0,25 \%)$ & 7,5 & 7,5 \\
Estabilizante $(0,25 \%)$ & 7,5 & 7,5 \\
Condimento $(1,0 \%)$ & 30,0 & 30,0 \\
Fumaça líquida $(0,5 \%)$ & 15,0 & - \\
\hline
\end{tabular}

\subsection{PROCESSAMENTO DAS LINGUIÇAS}

Para o processamento das linguiças os filés foram descongelados por aproximadamente 24 horas a $6 \pm 2{ }^{\circ} \mathrm{C}$ e processados em um moedor de carne com disco de $8 \mathrm{~mm}$ de abertura. Em seguida, a matéria-prima cárnea foi pesada e homogeneizada com os demais ingredientes em uma misturadeira de massas, introduzidas com o auxílio de uma embutideira manual em tripas naturais suínas (30-32 mm de diâmetro) previamente dessalgadas por $2 \mathrm{~h}$ de antecedência, amarradas com barbantes de algodão manualmente de modo que cada linguiça apresentou aproximadamente $6 \mathrm{~cm}$ de comprimento.

\subsubsection{Processo de defumação tradicional}

As linguiças foram cozidas em água fervente a $100{ }^{\circ} \mathrm{C}$ por 10 minutos até a temperatura alcançar aproximadamente $80^{\circ} \mathrm{C}$, resfriadas em água gelada $\left(4 \pm 2{ }^{\circ} \mathrm{C}\right)$ e armazenadas por $24 \mathrm{~h}$ a $6 \pm 2{ }^{\circ} \mathrm{C}$. Após este período, as linguiças foram penduradas em ganchos dentro de um defumador de alvenaria, mantida a porta do defumador aberta e secas no próprio defumador com o calor da queima da madeira (troncos de goiabeira) durante $30 \mathrm{~min}$ com o objetivo de retirar o excesso de umidade superficial. Então, a porta do defumador foi fechada e a defumação foi iniciada a $60{ }^{\circ} \mathrm{C}$ por $30 \mathrm{~min}$ e a temperatura controlada para não ultrapassar $80-90^{\circ} \mathrm{C}$ durante $3 \mathrm{~h}$. 


\subsubsection{Processo de defumação líquida}

As linguiças foram cozidas em água fervente $100{ }^{\circ} \mathrm{C}$ por 10 minutos até a temperatura alcançar aproximadamente $80^{\circ} \mathrm{C}$, resfriadas em água gelada $\left(4 \pm 2^{\circ} \mathrm{C}\right)$ e armazenadas por $24 \mathrm{~h}$ a $6 \pm 2{ }^{\circ} \mathrm{C}$. Em seguida, foram colocadas em bandejas e alojadas dentro de uma estufa de circulação de ar forçado a $60{ }^{\circ} \mathrm{C}$ por 30 min para retirar o excesso de umidade superficial. Após este período as linguiças foram retiradas da estufa, aplicado fumaça líquida por aspersão na diluição com água de $20 \%$ e novamente retornadas a estufa na temperatura de $80^{\circ} \mathrm{C}$ por mais $3 \mathrm{~h}$.

\subsubsection{Pós defumação}

Após o processo de defumação, as linguiças foram resfriadas a $6 \pm 2{ }^{\circ} \mathrm{C}$ durante aproximadamente $1 \mathrm{~h}$, acondicionadas em sacos plásticos de polietileno (Nylon Poli - 18X25X0,12 $\mathrm{cm}, 120$ micras), cada um deles contendo 3 unidades de linguiças, submetido à vácuo de $720 \mathrm{~mm} /$ $\mathrm{Hg}$ de pressão durante $25 \mathrm{~s}$ e armazenadas resfriadas a $6 \pm 2{ }^{\circ} \mathrm{C}$ até o momento das análises.

\subsection{ANÁLISES LABORATORIAIS}

\subsubsection{Composição Nutricional}

A composição nutricional das linguiças defumadas (líquida ou tradicional) foram determinadas em triplicata de acordo com a metodologia oficial da AOAC (2012). A proteína bruta foi determinada pelo método de Kjeldahl $(\mathrm{N} \times 6,25)$, gordura foi extraída com éter de petróleo em um extrator tipo Soxhlet, umidade foi calculada por gravimetria em estufa com circulação de ar a $105^{\circ} \mathrm{C}$ até peso constante e o conteúdo de cinzas por meio de incineração em mufla a $550^{\circ} \mathrm{C}$ por 5 horas.

\subsubsection{Perda de peso na defumação}

A porcentagem da perda de peso após a defumação foi calculada através da Equação 1 :

$$
\% \text { Perda de peso }=\frac{(\text { Peso da linguiça crua-Peso da linguiça defumada })}{\text { Peso da linguiça crua }} X 100
$$

\subsubsection{Encolhimento na defumação}

A porcentagem de encolhimento das linguiças após a defumação foi calculada de acordo com a Equação 2:

$$
\% \text { Encolhimento }=\frac{(\text { Comprimento linguiça crua-Comprimento linguiça defumada })}{\text { Comprimento linguiça crua }} \times 100
$$

\subsubsection{Capacidade de retenção de água}

Para a análise de capacidade de retenção de água foram pesados cinco gramas de três linguiças pré-homogeneizadas de cada tratamento, utilizando cada amostra em triplicata. As amostras foram colocadas em papéis filtros, alojados em tubos tipo Falcon e centrifugados a 3.500 RPM durante 10 minutos. Após, as amostras foram retiradas cuidadosamente dos papeis, pesadas e a capacidade de retenção de água foi calculada segundo GRAU \& HAMM (1953) (Equação 3):

$$
\% C R A=\frac{\text { Peso da amostra depois da centrifugação }}{\text { Peso da amostra antes da centrifugação }} X 100
$$

\subsubsection{Textura Instrumental}

A análise de Perfil de Textura Instrumental (TPA) foi realizada em um analisador de textura (TACT3, Brookfield ${ }^{\circledR}$,

Middleboro, USA). Três linguiças de cada tratamento foram cortadas em fatias de $20 \mathrm{~mm}$ de comprimento, comprimidas $50 \%$ deste tamanho utilizando um probe modelo TA25/1000 com velocidade 
do pré-teste, teste e pós-teste de $2 \mathrm{~mm} / \mathrm{s}$ a temperatura de $25^{\circ} \mathrm{C}$ de acordo com BOURNE (2002). Os parâmetros estudados foram: dureza $(\mathrm{g})$, elasticidade $(\mathrm{mm})$ e coesividade (admissional).

\subsubsection{Cor Instrumental}

A cor instrumental foi determinada em triplicata de três linguiças de cada tratamento. As linguiças foram cortadas longitudinalmente e as medidas de cor foram realizadas na região interna e externa. Foi utilizado um colorímetro portátil modelo CR 400 (Konica Minolta ${ }^{\circledR}$, Tókio, Japão), previamente calibrado com um padrão branco antes de cada análise, operando com fonte de luz uma lâmpada de xenônio, iluminante $C(Y=92.78 ; x=0.3139 ; y=0.3200)$, ângulo de observação de $40^{\circ}$ e área de medição de $8 \mathrm{~mm}$ de diâmetro. A cor foi expressa utilizando-se os padrões de cor do sistema CIELab - "Comission Internationale de L'Eclairage": $L^{*}$ (luminosidade), $a^{*}$ (intensidade da cor vermelha a verde) e $b^{*}$ (intensidade da cor amarela a azul).

\subsubsection{Determinação do $\mathrm{pH}$}

$\mathrm{O} \mathrm{pH}$ foi determinado com o emprego de um peagâmetro com eletrodo de imersão, previamente calibrado com soluções-tampão de pH 4 e 7, em uma solução de $10 \mathrm{~g}$ de amostra de linguiças defumadas previamente homogeneizadas com $40 \mathrm{~mL}$ de água destilada de acordo com OLIVEIRA FILHO et al. (2012).

\subsubsection{Atividade de água}

A atividade de água foi determinada em triplicata, utilizando-se três linguiças de cada tratamento pré-homogeneizadas em um processador de alimentos a temperatura de $25^{\circ} \mathrm{C}$ em um equipamento específico para este fim (Aqualab CX-2, Decagon Devices, Pullman, USA).

\subsubsection{Análises Bacteriológicas}

As análises bacteriológicas das linguiças defumadas foram realizadas para a contagem de aeróbios psicrotróficos, coliformes totais, Escherichia coli, Staphylococcus coagulase positiva e presença ou ausência de Salmonella spp. utilizando kits comerciais Compact Dry ${ }^{\circledR}$, os quais são aprovados pela Codex Alimentarius, I.C.M.S.F., APHA, FDA e AOAC para ensaios bacteriológicos de alimentos.

\subsection{DELINEAMENTO EXPERIMENTAL E ANÁLISE ESTATÍSTICA}

O delineamento experimental utilizado foi o inteiramente casualizado com 2 tratamentos (linguiças submetidas a defumação liquida e tradicional) e três repetições cada (três exemplares de linguiças). Foram primeiramente analisados a normalidade e a homocedasticidade. Como os dados apresentaram distribuição normal foi aplicado o Teste-t de Student com o nível de significância de $5 \%(P<0,05)$. As análises foram realizadas com o auxílio do programa estatístico SigmaStat $3.5^{\circledR}$.

\section{RESULTADOS E DISCUSSÃO}

\subsection{COMPOSIÇÃO NUTRICIONAL}

A umidade das linguiças não apresentaram variação $(P>0,05)$ quanto ao tipo de defumação utilizado (Tabela 2) e foram próximas ao observado em linguiças de Clarias slazera $(71,91 \%)$, Tetradon fahara $(72,73 \%)$, Clarias lazera + Tetradon fahara (70,0\%) (AHMED \& ELHAJ, 2011), salsichas elaboradas com $60 \%$ de carne mecanicamente separada (CMS) de resíduos de filetagem de tilapias do Nilo (Oreochromis niloticus) sem lavar (71,28\%), salsichas elaboradas com $100 \%$ de CMS de resíduos de filetagem de tilapias do Nilo sem lavar (70,78\%), salsichas elaboradas com $80 \%$ de CMS de resíduos de filetagem de tilapias do Nilo com 1 lavagem $(72,26 \%)$ (OLIVEIRA FILHO et al., 2012), salsicha de "Meagre" (Argyrosomus regius) (72,4\%) (RIBEIRO et al., 2013). Este resultado mostra que a umidade das linguiças defumadas do presente estudo são compatíveis com outros embutidos de pescado. 


\section{TABELA 2 - COMPOSIÇÃO NUTRICIONAL (MÉDIA \ DESVIO PADRÃO) DE LINGUIÇAS ELABORADAS COM FILÉS DE TILÁPIAS DO NILO (OREOCHROMIS NILOTICUS) SUBMETIDAS A DEFUMAÇÃO LÍQUIDA E TRADICIONAL}

\begin{tabular}{|c|c|c|}
\hline \multirow{2}{*}{ Composição nutricional (\%) } & \multicolumn{2}{|c|}{ Tipos de defumação } \\
\hline & Defumação líquida & Defumação tradicional \\
\hline Umidade & $71,08 \pm 0,88$ & $72,79 \pm 0,73^{\text {ns }}$ \\
\hline Proteína Bruta & $26,13 \pm 0,82$ & $24,25 \pm 0,79^{*}$ \\
\hline Gordura & $1,22 \pm 0,07$ & $1,16 \pm 0,07^{\mathrm{ns}}$ \\
\hline Cinzas & $2,69 \pm 0,11$ & $2,58 \pm 0,12^{\mathrm{ns}}$ \\
\hline
\end{tabular}

Tndica diferença significativa $(P<0,05)$.

A proteína é um dos principais nutrientes contidos nos alimentos para a boa saúde dos seres humanos tendo como principais funções ser constituinte do músculo e hormônios (CONTRERASGUZMÁN, 2002). As linguiças de tilápias submetidas a defumação líquida apresentaram maior $(P<0,05)$ quantidade de proteína que naquelas submetidas ao processo de defumação tradicional (Tabela 2). As salsichas defumadas de salmão suplementado com óleo de salmão (22,43\%) (OLIVEIRA et al., 2014), salsicha comercial de "Geelbeck croaker" (Atractoscion aequidens) $(20,16 \%)$ (RAHMAN et al., 2007) e salsichas elaboradas com filés de tilápias do Nilo $(20,86 \%)$ (OLIVEIRA FILHO et al., 2010) também apresentaram valores de proteína acima de $20 \%$.

As linguiças de filés de tilápias apresentaram aproximadamente $1 \%$ de gordura sem diferença $(P>0,05)$ entre tratamentos (Tabela 2). A baixa quantidade de gordura se deve ao fato de não ter sido utilizado na formulação gordura externa, além do filé de tilápias ser um alimento com baixa quantidade de gordura (AIURA \& CARVALHO, 2004). As linguiças elaboradas com carne de Clarias slazera (1,93\%), Tetradon fahara (1,31\%) (AHMED \& ELHAJ, 2011), salsichas elaboradas com $60 \%$ de CMS de resíduos de filetagem de tilápias (Oreochromis niloticus) submetida a 2 lavagens (1,65\%) (OLIVEIRA FILHO et al., 2012), salsichas de "meagre" (Argyrosomus regius) (1,3\%) (RIBEIRO et al., 2013), alguns tipos de salsichas de pescado comercializados na Malásia (0,93 a 2,02\%) (HUDA et al., 2012), salsichas elaboradas com filés de tilápias do Nilo <1\% (OLIVEIRA FILHO et al., 2010) apresentaram quantidade de gordura próxima ao do presente estudo.

As cinzas correspondem a matéria mineral presente no produto e pode ser influenciado pelo tipo de matéria-prima além dos ingredientes e aditivos utilizados na formulação dos produtos de pescado (OLIVEIRA FILHO et al., 2012). A quantidade de cinzas das linguiças foram muito próximas e não apresentaram diferença $(P>0,05)$ entre os tipos de defumação utilizada (Tabela 2). Isto pode ter ocorrido devido as matérias primas serem as mesmas e os ingredientes e aditivos terem sido adicionados na mesma proporção nos dois tratamentos. Quando realiza-se a comparação com outros estudos observa-se que os valores de cinzas das linguiças defumadas do presente estudo foram próximas as linguiças de carne de Clarias slazera (2,5\%), Tetradon fahara $(2,78 \%$ ) (AHMED \& ELHAJ, 2011), salsicha com a mistura de $20 \%$ carne bovina com $50 \%$ de carne de "Talang queenfish" (Scomberoides commersonnianus) (2,51\%) (HASHEMI \& JAFARPOUR, 2016), salsichas de "Sea Meagre" (Argyrosomus heinii) (2,5\%) (AL-BULUSHI et al., 2013), salsichas defumadas de salmão suplementado com óleo de salmão (2,7\%) (OLIVEIRA et al., 2014), salsicha com surimi de pescado (2,52 a 2,56\%) (SANTANA et al., 2015) e linguiças de filés de tilápias do Nilo sem adição de bacon $(2,1 \%)$ (MARQUES et al., 2012). 
A composição química permitida para as linguiças dessecadas ou defumadas elaboradas com carne de animais terrestres são as seguintes: umidade (máxima): $55 \%$, gordura (máxima): 30\%, proteína (mínimo): 15\% (BRASIL, 2000). Quando compara-se com as linguiças defumadas elaboradas com carne de tilápias observa-se que somente a umidade está acima do permitido pela legislação. Isto pode ter ocorrido devido as características próprias da composição nutricional da carne das tilápias e também por não ter sido adicionado nenhuma gordura externa. No entanto, a legislação brasileira não faz menção a linguiças defumadas elaboradas com carne de pescado.

\subsection{PERDA DE PESO, ENCOLHIMENTO E CAPACIDADE DE RETENÇÃO DE ÁGUA}

As linguiças de tilápias submetidas a defumação líquida apresentaram maior $(P<0,05)$ perda de peso que naquelas submetidas a defumação tradicional (Tabela 3). A perda de peso durante o processamento de produtos cárneos pode ser influenciada pelo tempo de processamento, temperatura de cozimento, integridade e quantidade de proteína da matériaprima cárnea e utilização de agentes ligantes como amidos e fosfatos (HUDA et al., 2012). Em produtos defumados a perda de peso varia entre 10 a 25\% (DALLABONA et al., 2013). No presente estudo, a principal fonte de variação foi o tipo de defumação na qual a líquida utilizou um concentrado de fumaça líquida e aquecimento em estufa. Enquanto que na defumação tradicional utilizou-se a câmara de combustão da madeira para fazer o aquecimento das linguiças. Portanto, os tipos de processos podem ter influenciado na perda de peso nas linguiças. Como nas linguiças submetidas a defumação líquida ocorreu maior perda de peso, esta poderia ser a explicação do menor conteúdo de umidade em relação as linguiças submetidas a defumação tradicional (Tabela 2). Resultados próximos ao do presente estudo foram observados em salsichas com carne de tambaquis (24,21 a 26,59\%) (SLEDER et al., 2015) e também em linguiças defumadas elaboradas com carne mecanicamente separada (CMS) de resíduos de filetagem de tilápias do Nilo (24,5\%) (DALLABONA et al., 2013).

A porcentagem de encolhimento das linguiças elaboradas com filés de tilápias do Nilo durante o processamento não foi influenciada $(P>0,05)$ pelo tipo de defumação realizada (Tabela 3). $O$ encolhimento de produtos processados é causado principalmente pela perda de água durante o cozimento e da junção da matéria-prima cárnea com os demais ingredientes (SÁ VIEIRA et al., 2015). Não foi observado na literatura trabalhos avaliando o encolhimento de embutidos de pescado durante o processamento. Em fishburger utilizando carne de tilápias com adição de diferentes quantidades de amido de milho observou-se variação no encolhimento durante o cozimento entre 10,03 a 16,72\% (SÁ VIEIRA et al., 2015), ou seja próximo ao observado nas linguiças de filés de tilápias do Nilo do presente estudo.

A capacidade de retenção de água (CRA) mede a habilidade da carne em reter água quando submetida a agentes externos como pressão ou centrifugação (OLIVEIRA FILHO et al., 2017). As linguiças de filés de tilápias submetidas a defumação tradicional apresentaram maior $(P<0,05)$ CRA que naquelas submetidas a defumação líquida (Tabela 3$)$. Esta diferença na CRA das linguiças pode ter ocorrido pelas variações dos diferentes tipos de defumação. Segundo SANTANA et al. (2013) a perda de água durante o cozimento e secagem da carne do pescado conduz a agregação da proteína causando perda da estrutura tridimensional da proteína na qual resulta na desnaturação proteína e diminuição da CRA. Como nas linguiças submetidas a defumação líquida ocorreu maior perda de peso durante o processamento pode ter causado a menor CRA das linguiças. As linguiças elaboradas com carne de tambaqui apresentaram CRA próximas (71 a $74 \%$ ) as linguiças de tilápias submetidas a defumação liquida (SLEDER et al., 2015). No entanto, salsichas elaboradas com carne de peixes de água doce adicionado $3,5 \%$ de amido de tapioca a CRA (96,46\%) foram próximas (PRABPREE \& PONGSAWATMANIT, 2011) das linguiças de filés de tilápias submetidas a defumação tradicional. Isto mostra que os tipos de cozimento e defumação, presença aditivos e amido podem influenciar na CRA dos embutidos de pescado. 


\section{TABELA 3 - ANÁLISES FÍSICAS DE PERDA DE PESO, ENCOLHIMENTO E CAPACIDADE DE RETENÇÃO DE ÁGUA (MÉDIA \ DESVIO PADRÃO) DE LINGUIÇAS ELABORADAS COM FILÉS DE TILÁPIAS DO NILO (OREOCHROMIS NILOTICUS) SUBMETIDAS A DEFUMAÇÃO LÍQUIDA E TRADICIONAL}

Tipos de defumação

\begin{tabular}{lcc} 
Análises físicas $(\%)$ & Defumação líquida & Defumação tradicional \\
\cline { 2 - 3 } & $25,73 \pm 1,05$ & $20,49 \pm 0,17^{*}$ \\
Perda de peso & $19,17 \pm 7,59$ & $13,14 \pm 6,92^{\text {ns }}$ \\
$\begin{array}{l}\text { Encolhimento } \\
\text { de água }\end{array}$ & $74,03 \pm 10,15$ & $92,56 \pm 0,54^{*}$ \\
\hline Tndica diferença significativa $(P<0,05)$.
\end{tabular}

\subsection{TEXTURA INSTRUMENTAL}

Os quesitos físicos de dureza, coesividade e elasticidade não foram influenciados $(P>0,05)$ pelo tipo de defumação utilizado nas linguiças de tilápias (Tabela 4). Os fatores físico-químicos que mais influenciam na textura dos embutidos cárneos são a umidade, proteínas e gorduras. Como eles foram muito próximos entre as linguiças submetidas aos dois tipos de defumação, isso pode ser a explicação da falta de variação na textura instrumental.

\section{TABELA 4 - TEXTURA INSTRUMENTAL (MÉDIA \pm DESVIO PADRÃO) DE LINGUIÇAS ELABORADAS COM FILÉS DE TILÁPIAS DO NILO (OREOCHROMIS NILOTICUS) SUBMETIDAS A DEFUMAÇÃO LÍQUIDA E TRADICIONAL}

Tipos de defumação

Textura instrumental

$$
\text { Defumação líquida }
$$

$5.134,67 \pm 3.969,61$

$0,94 \pm 0,02$

Coesividade (admissio-

nal)

Elasticidade $(\mathrm{mm})$
Defumação tradicional

$3.259,33 \pm 1.325,90^{\text {ns }}$

$0,94 \pm 0,01^{\text {ns }}$

$2,39 \pm 0,06^{\text {ns }}$

Tndica diferença significativa $(P<0,05)$.

A dureza de um produto alimentício é a medição da força necessária para produzir certa deformação, e é demonstrado pelo pico de força durante a primeira compressão (BOURNE, 2002). A dureza das linguiças defumadas do presente estudo foram próximas ao observado em salsichas elaboradas com surimi de pescado $(4.137,90$ a $5.843,80 \mathrm{~g})$ (SANTANA et al., 2015), salsichas de pescado comercializadas na Malásia (3.280 a $5.670 \mathrm{~g}$ ) (HUDA et al., 2012) e salsichas elaboradas com 60, 80 e 100\% de CMS de tilápia sem lavar e com 1 lavagem (3.146 a $3.891 \mathrm{~g}$ ) (OLIVEIRA FILHO et al., 2012). Segundo HUDA et al. (2012) embutidos de pescado 
que apresentam dureza acima de $4.730 \mathrm{~g}$ geralmente são bem aceitos pelos consumidores para o atributo textura. Ou seja, de acordo com esta informação a textura das linguiças defumadas de tilápias do Nilo podem ser bem aceitas pelo mercado consumidor. No entanto, vale ressaltar que fatores culturais, religiosos e geográficos também podem influenciar na aceitação dos produtos alimentícios (UYHARA et al., 2008).

A coesividade é a medida da extensão que um alimento pode ser deformado antes da ruptura (BOURNE, 2002). A coesividade das linguiças de tilápias do presente estudo foram superiores ao observado em outros embutidos de pescado, tais como: salsicha elaboradas com surimi de pescado $(0,29$ a 0,31) (SANTANA et al., 2015), salsichas de pescado comercializadas na Malásia $(0,28$ a 0,42) (HUDA et al., 2012), salsicha de "Talang queenfish" (Scomberoides commersonnianus) $(0,51$ a 0,68$)$ (HASHEMI \& JAFARPOUR, 2016), salsichas elaboradas com CMS de resíduos de filetagem de tilápias do Nilo $(0,13$ a 0,63) (OLIVEIRA FILHO et al., 2010), salsichas de pescado de água doce elaboradas com diferentes concentrações de amido de tapioca $(0,56$ a 0,58$)$ (PRABPREE \& PONGSAWATMANIT, 2011), salsichas de trutas ou "saithes" $(0,33$ a $0,37)$ (DINÇER \& ÇAKLI, 2015). Como as linguiças defumadas de filés de tilápias apresentaram alta porcentagem de proteínas, esta poderia ser a causa da alta coesividade das linguiças. Além disso, outros fatores também podem influenciar na coesividade dos produtos de pescado tais como: porcentagem de umidade, gordura, variações nas formulações e formas de processamento (DINÇER \& ÇAKLI, 2015).

A elasticidade é medida da habilidade que uma amostra possui em recuperar sua altura original após remoção da força de compressão (BOURNE, 2002). Este quesito de textura é influenciado pela composição química e espessura do embutido de pescado analisado (DINÇER \& ÇAKLI, 2015). As salsichas de pescado de água doce elaborada com diferentes concentrações de amido de tapioca (3,92 a 4,11 mm) (PRABPREE \& PONGSAWATMANIT, 2011), salsichas de trutas ou "saithes" (0,5 a 0,84 mm) (DINÇER \& ÇAKLI, 2015) apresentaram valores próximos ao observado nas linguiças defumadas de tilápias.

\subsection{COR INSTRUMENTAL}

A cor dos alimentos é um dos principais atrativos pelo consumidor na hora de efetuar a compra dos produtos (UYHARA et al., 2008). Os parâmetros de cor instrumental da região interna e externa das linguiças de filés de tilápias do Nilo submetidas a diferentes tipos de defumação estão demonstrados na Tabela 5. Os valores de $L^{*}$ (luminosidade) não apresentaram variação $(P>0,05)$ na região interna das linguiças entre os tipos de defumação testado e foram ligeiramente superior a região externa. Isto pode ter ocorrido devido o processo de defumação tradicional e líquida ser realizada com calor e com isso promover a reação de Maillard que tende a escurecer os alimentos. No entanto, a região externa das linguiças de filés de tilápias submetidas a defumação líquida foram mais $(P<0,05)$ luminosas (maior valor de $L^{*}$ ) que naquelas submetidas a defumação tradicional. Isto pode ter ocorrido devido as linguiças submetidas a defumação tradicional ficar totalmente envolvida com a fumaça e assim causar maior caramelização. As linguiças elaboradas com CMS de resíduos de filetagem de tilápia do Nilo submetidas ao processo de defumação tradicional apresentaram valor de $L^{*}$ de 55,0 (DALLABONA et al., 2013). Se for comparado com as linguiças do presente estudo observa-se valor mais próximo com o tratamento das linguiças submetidas a defumação líquida em relação a defumação tradicional. Em outro estudo utilizando carne de salmão suplementado com óleo de salmão para a elaboração de linguiças defumadas pelo método tradicional o valor de $L^{*}$ foi de 64,71 (OLIVEIRA et al., 2014). Estas variações podem ter ocorrido pelas diferentes formulações, distintas formas de processamento e características naturais da luminosidade (valor de $L^{*}$ ) das carnes utilizadas para a elaboração das linguiças. 


\section{TABELA 5 - COR INSTRUMENTAL (MÉDIA \ DESVIO PADRÃO) DA REGIÃO INTERNA E DA REGIÃO EXTERNA DE LINGUIÇAS ELABORADAS COM FILÉS DE TILÁPIAS DO NILO (OREOCHROMIS NILOTICUS) SUBMETIDAS A DEFUMAÇÃO LÍQUIDA E TRADICIONAL ${ }^{1,2}$}

\begin{tabular}{|c|c|c|c|c|}
\hline \multirow[t]{3}{*}{ Cor } & \multicolumn{4}{|c|}{ Tipos de defumação } \\
\hline & \multicolumn{2}{|c|}{ Defumação líquida } & \multicolumn{2}{|c|}{ Defumação tradicional } \\
\hline & Região interna & Região externa & Região interna & Região externa \\
\hline$L^{*}$ & $\begin{array}{l}59,71 \pm \\
0,95^{a}\end{array}$ & $\begin{array}{l}51,43 \pm \\
0,45 A\end{array}$ & $\begin{array}{l}59,61 \pm \\
1,47^{a}\end{array}$ & $\begin{array}{l}45,89 \pm \\
2,31 \mathrm{~B}\end{array}$ \\
\hline$a^{*}$ & $\begin{array}{l}1,56 \pm \\
0,28^{\mathrm{b}}\end{array}$ & $\begin{array}{l}2,98 \pm \\
0,46 \mathrm{~B}\end{array}$ & $\begin{array}{l}2,20 \pm \\
0,11^{a}\end{array}$ & $\begin{array}{l}6,52 \pm \\
0,66 \mathrm{~A}\end{array}$ \\
\hline$b^{*}$ & $\begin{array}{l}9,64 \pm \\
0,15^{\mathrm{a}}\end{array}$ & $\begin{array}{l}13,25 \pm \\
0,17 \mathrm{~B}\end{array}$ & $\begin{array}{l}8,81 \pm \\
0,71^{a}\end{array}$ & $\begin{array}{l}24,33 \pm \\
1,25 \mathrm{~A}\end{array}$ \\
\hline
\end{tabular}

Os processos de defumação das linguiças causaram variações $(P<0,05)$ nos valores de $a^{*}$ (intensidade de vermelho) tanto na região interna como na região externa. As linguiças submetidas a defumação tradicional foram mais vermelhas na região interna e externa que naquelas submetidas a defumação líquida. Em concordância com as linguiças defumadas pelo método tradicional do presente estudo, as linguiças defumadas da mesma forma elaboradas com CMS de resíduos de filetagem de tilápia do Nilo apresentaram intensidade de vermelho de 6,16 (DALLABONA et al., 2013).

A intensidade de amarelo (valor de $b^{*}$ ) da região externa das linguiças de filés de tilápias do Nilo submetidas a defumação tradicional foram superiores $(P<0,05)$ em relação aquelas submetidas a defumação líquida. Este fenômeno pode ter ocorrido devido o processo de defumação tradicional, utilizando fumaça oriunda da queima da madeira, causar mais mudanças na coloração que nas linguiças submetidas a fumaça líquida. As linguiças elaborada com CMS de resíduos de filetagem de tilápia do Nilo submetidas a defumação tradicional apresentaram valor de $b^{*}$ de 13 (DALLABONA et al., 2013). Em outro estudo, o valor de $b^{*}$ de salsichas elaboradas com salmão e suplementado com óleo de salmão e submetidas a defumação tradicional foi de 23,36 (OLIVEIRA et al., 2014). Estes estudos mostram que a intensidade de amarelo das linguiças defumadas são próximas se for aplicado a defumação tradicional ou então com a defumação líquida.

\subsection{PH E ATIVIDADE DE ÁGUA}

$\mathrm{O}$ pH das linguiças não foi alterado pelo processo de defumação (Tabela 6) e permaneceram abaixo do máximo exigido pela legislação brasileira para pescado fresco que é de 6,8 (DALLABONA et al., 2013). Em outro estudo com linguiça de pescado (C. regium, L.mystaceus e C. trutta) também não foi verificado variação no $\mathrm{pH}$ com o processo de defumação líquida ou tradicional (OZPOLAT \& PATIR, 2015), mostrando que o tipo de defumação não altera os valores de $\mathrm{pH}$ da linguiças de pescado. As linguiças elaboradas com CMS de resíduos de filetagem de tilápias do Nilo submetidas 
a defumação tradicional apresentaram valor de pH de 6,42 (BARTOLOMEU et al., 2014), próximo do encontrado nas linguiças do presente estudo.

A atividade de água mede a água que não está conjugada com outros componentes em uma estrutura cárnea sendo a mais utilizada pelas bactérias para o seu desenvolvimento (HOFFMANN, 2001). A atividade de água das linguiças do presente estudo não apresentaram diferença $(P>0,05)$ entre os métodos de defumação aplicados (Tabela 6$)$ e foram próximas ao observado em linguiças elaboradas com CMS de resíduos de filetagem de tilápias do Nilo $(0,98)$ (OLIVEIRA FILHO et al., 2010), mortadelas elaboradas com CMS de resíduos de filetagem de tilápias do Nilo $(0,98)$ (BARTOLOMEU et al., 2014) e linguiças de C. regium, L.mystaceus e C. trutta submetidas ao processo de defumação líquida ou tradicional $(0,95-0,97)$ (OZPOLAT \& PATIR, 2015). O valor observado no presente estudo de atividade de água, assim como nos estudos citados, mostra que são alimentos com grande possibilidade de desenvolvimento microbiano pois são ligeiramente inferior a 1, necessitando portanto armazenagem refrigerada (OLIVEIRA FILHO et al., 2010).

\section{TABELA 6 - AVALIAÇÃO DO PH E ATIVIDADE DE ÁGUA (MÉDIA \pm DESVIO PADRÃO) DE LINGUIÇAS ELABORADAS COM FILÉS DE TILÁPIAS DO NILO (OREOCHROMIS NILOTICUS) SUBMETIDAS A DEFUMAÇÃO LÍQUIDA E TRADICIONAL}

Tipos de defumação

Quesitos avaliados

Defumação líquida

$6,62 \pm 0,04$

$0,97 \pm 0,01$

$\mathrm{pH}$

Atividade de água

Tndica diferença significativa $(P<0,05)$.

\subsection{ANÁLISES BACTERIOLÓGICAS}

As linguiças de filés de tilápias submetidas a defumação a líquida e tradicional foram ausentes de Salmonella spp. (Tabela 7). Além disso, a contagem total de bactérias aeróbias psicrotróficas, Escherichia coli e Staphylococcus coagulase positiva foram inferiores a 2 log UFC/g. Em concordância com o presente estudo, mortadelas defumadas pelo processo tradicional, elaboradas com carne CMS de resíduos de filetagem de tilápias do Nilo, também não apresentaram presença de bactérias patogênicas (BARTOLOMEU et al., 2014). A queima de madeira com a geração da fumaça forma compostos antimicrobianos como ácidos orgânicos, álcoois, carbonilas e hidrocarbonetos que combatem o desenvolvimento de bactérias (SAMPLES, 2015). Isto pode ter sido o motivo pela ausência de bactérias patogênicas. Outra explicação se deve ao fato do processamento ter ocorrido de forma higiênica.

Segundo BRASIL (2001) o pescado e produtos de pescado podem conter no máximo, os seguintes graus de contaminação bacteriana: coliformes fecais (Escherichia coli) máximo de $10^{3} \mathrm{UFC} / \mathrm{g}$, Staphylococcus coagulase positiva máximo $10^{3} \mathrm{UFC} / \mathrm{g}$, Salmonella spp. ausência em $25 \mathrm{~g}$ de amostra, não havendo limites para coliformes totais e contagem total de bactérias aeróbias psicrotróficas e mesófilas. Portanto, as linguiças de filés de tilápias submetidas a defumação liquida e tradicional podem ser consumidas por estar em conformidade com o padrão sanitário vigente. 


\section{TABELA 7 - AVALIAÇÃO BACTERIOLÓGICA DE LINGUIÇAS ELABORADAS COM FILÉS \\ DE TILÁPIAS DO NILO (OREOCHROMIS NILOTICUS) SUBMETIDAS A DEFUMAÇÃO \\ LÍQUIDA E TRADICIONAL}

\begin{tabular}{|c|c|c|}
\hline \multirow{2}{*}{ Bactérias } & \multicolumn{2}{|c|}{ Tipos de defumação } \\
\hline & Defumação líquida & Defumação tradicional \\
\hline Escherichia coli (log UFC/g) & $<2$ & $<2^{\text {ns }}$ \\
\hline Salmonella spp. (25g amostra) & Ausente & Ausente \\
\hline $\begin{array}{c}\text { Staphylococcus coagulase positi- } \\
\text { va (log UFC/g) }\end{array}$ & $<2$ & $<2^{\text {ns }}$ \\
\hline $\begin{array}{c}\text { Aeróbios psicrotróficos (log } \\
\text { UFC/g) }\end{array}$ & $<2$ & $<2^{\text {ns }}$ \\
\hline
\end{tabular}

\section{CONCLUSÃO}

A defumação líquida causa melhora nos percentuais de proteínas, pouca variação nos aspectos físicos, químicos e bacteriológicos, sendo portanto um potencial substituto do método tradicional de defumação de linguiças de tilápias do Nilo.

\section{ABSTRACT \\ EVALUATION OF NILE TILAPIA (OREOCHROMIS NILOTICUS) SAUSAGES SUBMITTED TO DIFFERENT SMOKING METHODS}

One way of diversifying and stimulating fish consumption in Brazil may be through innovative products such as smoked sausages. Therefore, the objective of the present study was to evaluate nutritional (crude protein, fat, moisture and ash) physical (weight loss and shrinkage, water retention capacity, texture and instrumental color and $\mathrm{pH}$ ) and chemical (water activity) as well as bacteriological (Escherichia coli, Salmonella spp., Staphylococcus positive coagulase and psychrotrophic aerobic bacteria) aspects of Nile tilapia filleting sausages submitted to traditional and liquid smoking. The sausages submitted to liquid smoking presented higher protein percentage, higher $L^{*}$ value (lightness), lower $a^{*}$ (redness) and $b^{*}$ value (yellowness), but with greater weight loss during processing and lower water retention capacity. Moisture, fat, ash, percentage of shrinkage, instrumental texture, $\mathrm{pH}$, water activity and bacteriological analyzes were not influenced by both methods of smoking. Therefore, liquid smoking causes improvement in protein percentages, little variation on physical, chemical and bacteriological of sausages made with Nile tilapia filleting regarding traditional method, besides presenting greater ease of execution, less environmental pollution, easier cleaning after processing and less possibility of deposition carcinogenic chemical compounds, being a potential substitute for the traditional smoking method of Nile tilapia sausages.

KEY WORDS: TRADITIONAL SMOKING, LIQUID SMOKING, FISH SAUSAGES, OREOCHROMIS NILOTICUS. 


\section{REFERÊNCIAS}

1 AHMED, E.O.; ELHAJ, G.A. The chemical composition microbiological detection and sensory evaluation of fresh fish sausage made from Clarias lazera and Tetradon fahaka. Journal of Fisheries and Aquaculture, v.2, n.1, p.11-16, 2011.

2 AIURA, F.S.; CARVALHO, M.R.B. Composição em ácidos graxos e rendimento de filé de tilápia do Nilo (Oreochromis niloticus) alimentada com dietas contendo tanino. Revista Portuguesa de Ciências Veterinárias, v.99, p.93-98, 2004.

3 AL-BULUSHI, I.M.; KASAPIS, S.; DYKES, G.A.; AL-WAILI, H.; GUIZANI, N.; AL-OUFI, H. Effect of frozen storage on the characteristics of a developed and commercial fish sausages. Journal of Food Science and Technology, v.50, n.6, p.1158-1164, 2013.

4 ASSOCIATION OF OFFICIAL ANALYTICAL CHEMISTS (AOAC) 2012. Official methods of analysis of the AOAC. 19 edn. Gaithersburg, 2012.

5 BARTOLOMEU, D.A.F.S.; WASZCZYNSKYJ, N.; KIRSCHNIK, P.G.; DALLABONA, B.R.; COSTA, F.J.O.G.; LEIVAS, C.L. Storage of vacuum-packaged smoked bologna sausage prepared from Nile tilapia. Acta Scientiarum - Technology, v.36, n.3, p.561-567, 2014

6 BOURNE, M.C. Food texture and viscosity: concept and measurement. New York Academic Press, 2002. 427 p.

7 BOUZGARROU, O.; MZOUGUI, N.E.; SADOK, S. Smoking and polyphenols addition to improve freshwater mullet (Mugil cephalus) fillets quality attributes during refrigerated storage. International Journal of Food Science and Technology, v.51, n.1, p.268-277, 2016

8 BRASIL. Ministério da Agricultura, Pecuária e Abastecimento. Instrução Normativa n. 4 de 31 de março de 2000. Aprova os Regulamentos Técnicos de Identidade e Qualidade de Carne Mecanicamente Separada, de Mortadela, de Linguiça e de Salsicha. Diário Oficial [da] República Federativa do Brasil, Brasília, 05 abril de 2000, Seção 1, p.6-10.

9 BRASIL 2001. Disponível em: http://portal.anvisa.gov.br/documents/33880/2568070/RDC_12_2001.pdf/15ffddf6-37674527-bfac-740a0400829b. Acesso em: 02/12/2017.

10 CONTRERAS-GUZMÁN, E.S. Bioquímica de peixes e invertebrados. Cecta-Usach Press, Santiago, Chile, 2002.

11 COSTA, A.P.R.; ANDRADE, D.R.; VIDAL JÚNIOR, M.V.; CORDEIRO, C.A.M.; SOUZA, G.; ERTHAL JUNIOR, M.; SOUZA, C.L.M. Defumação de filés de piau-vermelho (Leporinus copelandii) com o uso de fumaça líquida. Revista Ceres, v.55, n.4, p.251-257, 2008.

12 DALLABONA, B.R.; KARAM, L.B.; WAGNER, R.; BARTOLOMEU, D.A.F.S.; MIKOS, J.D.; FRANCISCO, J.G.P.; MACEDO, R.E.F.; KIRSCHNIK, P.G. Effect of heat treatment and packaging systems on the stability of fish sausage. Revista Brasileira de Zootecnia, v.42, n.12, p.835-843, 2013.

13 DINÇER, M.T.; ÇAKLI, S. Textural acceptability of prepared fish sausage by controlling textural indicators. Turkish Journal of Veterinary and Animal Sciences, v.39, p.364-368, 2015.

14 FAO 2016. The State of World Fisheries and Aquaculture 2016. Contributing to food security and nutrition for all, $200 \mathrm{p}$. Rome.

15 GRAU, W.R.; HAMM, R. Muscle as food. In: BECHTEL, P.J. Food Science and Technology. New York: Academic Press, 1953. 54p.

16 HASHEMI, A.; JAFARPOUR, A. Rheological and microstructural properties of beef sausage batter formulated with fish fillet mince. Journal of Food Science and Technology, v.53, n.1, p.601-610, 2016.

17 HOFFMANN, F.L. Fatores limitantes à proliferação de microorganismos em alimentos. Brasil Alimentos, v.9, n.1, p.2330, 2001.

18 HUDA, N.; ALISTAIR, T.L.J.; LIM, H.W.; NOPIANTI, R. Some quality characteristics of Malaysian commercial fish sausage. Pakistan Journal of Nutrition, v.11, n.8, p.700-705, 2012.

19 MARQUES, L. F.; NUNES, J. S.; CASTRO, D. S.; ARAÚJO, L. K.; SALES, M. L. S. Avaliação da qualidade de linguiça de tilápia do Nilo (Oreochromis niloticus). Revista Semiárido De Visu, v.2, n.1, p.3-10, 2012.

20 OLIVEIRA FILHO, P.R.C.; NETTO, F.M.; RAMOS, K.K.; TRINDADE, M.A.; VIEGAS, E.M.M. Elaboration of sausage using minced fish of Nile tilapia filleting waste. Brazilian Archives of Biology and Technology, v.53, n.6, p.1383-1391, 2010.

21 OLIVEIRA FILHO, P.R.C.; SOBRAL, P.J.A.; BALIEIRO, J.C.C.; VIEGAS, E.M.M. Comparison of stunning methods on the physicochemical properties of frozen Nile tilapia (Oreochromis niloticus) fillets. Journal of Aquatic Food Product Technology, v.26, n.3, p.325-334, 2017.

22 OLIVEIRA FILHO, P.R.C.; VIEGAS, E.M.M.; KAMIMURA, E.S.; TRINDADE, M.A. Evaluation of physicochemical and sensory properties of sausages made with washed and unwashed mince from Nile tilapia by-products. Journal of Aquatic Food Product Technology, v.21, n.3, p.222-237, 2012. 
23 OLIVEIRA, A.C.M.; HIMELBLOOM, B.H.; MONTAZERI, N.; DAVENPORT, M.; BICEROGLU, H.; BRENNER, K.A.; THOMAS, S.R.; CRAPO, C.A. Development and characterization of fish sausages supplemented with salmon oil. Journal of Food Processing and Preservation, v.38, n.4, p.1641-1652, 2014.

24 OZPOLAT, E.; PATIR, B. Determination of shelf life for sausages produced from some freshwater fish using two different smoking methods. Journal of Food Safety, v.36, n.1, p.69-76, 2016.

25 PRABPREE, R.; PONGSAWATMANIT, R. Effect of tapioca starch concentration on quality and freeze-thaw stability of fish sausage. Kasetsart Journal (Natural Science), v.45, p.314-324, 2011.

26 RAHMAN, M.S.; AL-WAILI, H.; GUIZANI, N.; KASAPIS, S. Instrumental-sensory evaluation of texture for fish sausage and its storage stability. Fisheries Science, v.73, n.5, p.1166-1176, 2007.

27 RIBEIRO, B.; CARDOSO, C.; SILVA, H.A.; SERRANO, C.; RAMOS, C.; SANTOS, P.C.; MENDES, R. Effect of grape dietary fibre on the storage stability of innovative functional seafood products made from farmed meagre (Argyrosomus regius). International Journal of Food Science and Technology, v.48, n.1, p.10-21, 2013.

28 RIZO, A.; MAÑES, V.; FUENTES, A.; FERNÁNDEZ-SEGOVIA, I.; BARAT, J.M. Physicochemical and microbial changes during storage of smoke-flavoured salmon obtained by a new method. Food Control, v.56, p.195-201, 2015.

29 SÁ VIEIRA, P.H.; MELO, C.C.; MEDEIROS, R.F.; VASCONCELOS FILHO, M.B.V.; MOURA, J. V. S.; ALBUQUERQUE, C.A.; OLIVEIRA FILHO, P.R.C. Produtos de valor agregado de tilápia (Oreochromis niloticus) utilizando diferentes concentrações de amido. Acta of Fisheries and Aquatic Resources, v.3, n.1, p.41-53, 2015.

30 SAMPELS, S. The effects of processing technologies and preparation on the final quality of fish products. Trends in Food Science and Technology, v.44, n.2, p.131-146, 2015.

31 SANTANA, P.; HUDA, N.; YANG, T.A. Physicochemical properties and sensory characteristics of sausage formulated with surimi powder. Journal of Food Science and Technology, v.52, n.3, p.1507-1515, 2015.

32 SLEDER, F.; CARDOSO, D.A.; SAVAY-DA-SILVA, L.S.; ABREU, J.S.; OLIVEIRA, A.C.S.; ALMEIDA FILHO, E.S. Development and characterization of a tambaqui sausage. Ciência e Agrotecnologia, v.39, n.6, p.604-612, 2015.

33 SOUZA, M.L.R.; BACCARIN, A.E.; VIEGAS, E.M.M.; KRONKA, S.N. Defumação da tilápia do Nilo (Oreochromis niloticus) inteira eviscerada e filé: aspectos referentes às características organolépticas, composição centesimal e perdas ocorridas no processamento. Revista Brasileira de Zootecnia, v.33, n.1, p.27-36, 2004.

34 UYHARA, C.N.S.; OLIVEIRA FILHO, P.R.C.; TRINDADE, M.A.; VIEGAS, E.M.M. Adição de corantes em salsichas de tilápia do Nilo: efeito sobre a aceitação sensorial. Brazilian Journal of Food Technology, v.11, n.4, p.271-278, 2008.

\section{AGRADECIMENTOS}

Gostaríamos de agradecer a Economista Doméstica, Jaqueline Ferreira, técnica do Laboratório de Análise de Físico-química dos Alimentos do Departamento de Ciências Domésticas da UFRPE, pelo auxílio das análises laboratoriais. 